Received: 31.10 .2020

Revised: 10.12 .2020

Accepted: 18.12 .2020

DOI: $10.17804 / 2410-9908.2020 .6 .035-047$

\title{
A PECULIARITY OF THE MAGNETIZATION OF A FERROMAGNET BY AN ALTERNATING FIELD
}

\author{
Yu. Ya. Reutov \\ M.N. Miheev Institute of Metal Physics, Ural Branch of the Russian Academy of Sciences, \\ 18 S. Kovalevskoy St., Ekaterinburg, 620990, Russian Federation \\ هija1@yandex.ru \\ E-mail: asija1@yandex.ru \\ Address for correspondence: ul. S. Kovalevskoy, 18, Ekaterinburg, 620990, Russia
}

It has been experimentally established that the demagnetizing field of the magnetic poles formed at the ends of an open ferromagnetic cylinder decreases with increasing frequency of the magnetizing field due to a decrease in their size under the influence of the surface effect. For this reason, as the frequency of the magnetizing external field increases, the internal field in a ferromagnetic cylinder near the surface approaches it in amplitude. In addition, it has been found that the field on the surface of a ferromagnetic rod magnetized by an alternating field significantly exceeds the latter in strength with increasing frequency of this field.

Keywords: alternating magnetic field, surface effect, demagnetizing coefficient, magnetic poles, surface effect, eddy currents, internal field, penetration depth, Hall effect, microchip.

\section{Acknowledgment}

The work was performed under the state assignment from The Ministry of Education and Science of Russia (theme Diagnostics, No. AAAA-A18-118020690196-3).

\section{References}

1. Dorofeyev A.L. Nerozrushayushchiye ispytaniya metodom vikhrevykh tokov [Non-destructive eddy current testing]. Moscow, Publ. «Oborongiz», 1961, 158 p. (In Russian).

2. Lammeraner J., Štafl M. Vikhrevye toki, per. s chesh. [Vířivé proudy, Státní nakladatelství technické literatury, Praha, 1964]. Moscow, Leningrad, Energiya Publ., 1967, 208 p. (In Russian).

3. Gerasimov V.G., Ostanin Yu.Ya., Pokrovskij A.D., Sukhorukov V.V., Chernov L.A. Nerazrushayushchiy control kachestva izdeliy elektromagnitnymi metodami [Nondestructive Quality Testing of Articles by Electro-magnetic Methods]. Moscow, Energiya Publ., 1978, 216 p. (In Russian).

4. Nerazrushayushchiy control, pod red. V.V. Kluyeva, t. 2 [Non-destructive Testing, Kluyev V.V., ed., vol. 2]. Moscow, Mashinostroenie Publ., 2005, 688 p. (In Russian).

5. Reutov Y.Y., Shcherbinin V.E. On complex permeability in eddy-current flaw detection, defektoskopiya. Russian Journal of Nondestructive Testing, 2012, vol. 48, no. 12, pp. 693-699. DOI: $10.1134 / \mathrm{S} 1061830912120054$.

6. Reutov Yu.Ya. The causes of the hodograph anomalies of a vortex-current converter. Russian Journal of Nondestructive Testing, 2012, vol. 51, no. 12, pp. 759-767. DOI: 10.1134/ /S1061830915120086.

7. Reutov Yu.Ya. A generalized eddy current parameter: applicability boundaries. Elektrichestvo, 2016, no. 7, pp. 42-50. (In Russian). 
8. Arkadev V.K. Elektromagnitnye processy $v$ metallakh, ch. 2 [Electromagnetic Processes in Metals]. Moscow, Leningrad, NKTP SSSR, Obed. Nauch.-tekhnicheskoe izd-vo, Glavnaya Red. Energeticheskoy Literatury Publ., 1934-1936. (In Russian).

9. Chechernikov V.I. Magnitnye izmereniya [Magnetic Measurements]. Izdatelstvo Moskovskogo Universiteta, 1969, 386 p. (In Russian).

10. Turowski Janusz. Tehnicheskaya elektrodinamika, per. s polsk. [Elektrodynamika techniczna]. Moscow, Energiya, 1974, 488 p. (In Russian).

11. Burtsev G.A. On the magnetization reversal dynamics of finite-length ferromagnetic rods in weak magnetic fields. Defektoskopiya, 1973, no. 5, pp. 34-42. (In Russian).

12. Tamm I.E. Osnovy teorii elektrichestva [Fundamentals of the Theory of Electricity]. Moscow, Nauka Publ., 1976, 616 p. (In Russian).

13. Yanus R.I. Magnitnaya defektoskopiya [Magnetic Nondestrictive Testing]. Moscow, Leningrad, OGIZ Gostekhizdat Publ., 1946, 171 p. (In Russian).

14. Vedenev M.A., Drozhzhina V.I. On measurements of coercive force with a bolt-on probe. Defektoskopiya, 1977, no. 5, pp. 65-73. (In Russian).

15. Vedenev M.A. An instrument for measuring the tangential component of a constant magnetic field on the surface of a specimen. Defektoskopiya, 1982, no. 2, pp. 89-91. (In Russian).

16. Available at: www.sentron.ch

17. Reutov Y.Y., Shcherbinin V.E., Volkov A.V. Possibilities for the selection of magnetic field transducers for nondestructive testing. Russian Journal of Nondestructive Testing, 2014, vol. 50, no. 12, pp. 760-768. DOI: 10.1134/S1061830914120080.

18. Reutov Y.Y. The characteristic of an object revealed by its magnetic field. Russian Journal of Nondestructive Testing, 1998, vol. 34, no. 2, pp. 77-83.

19. Reutov Yu.Ya. Ferrite-ring magnetostatic screens. Russian Journal of Nondestructive Testing, 1999, vol. 35 (5), pp. 334-338. 
Подана в журнал: 31.10 .2020

УДК 620.179.14:620.179.147

DOI: $10.17804 / 2410-9908.2020 .6 .035-047$

\title{
ОСОБЕННОСТЬ НАМАГНИЧИВАНИЯ ФЕРРОМАГНЕТИКА ПЕРЕМЕННЫМ ПОЛЕМ
}

\author{
Ю. Я. Реутов \\ ФГБУН Институт физики металлов имени М.Н. Михеева Уральского отделения Российской академии наук, \\ 18, ул. С. Ковалевской, г. Екатеринбург, Российская Федерация \\ 冈asija1@yandex.ru \\ *Ответственный автор. Электронная почта: asija1 @ yandex.ru \\ Адрес для переписки: ул. С. Ковалевской, 18, 620990, г. Екатеринбург, Российская Федерация
}

Экспериментальным путем установлено, что размагничивающее поле магнитных полюсов, образующихся на торцах разомкнутого ферромагнитного цилиндра, убывает с ростом частоты намагничивающего поля вследствие уменьшения их размеров под влиянием поверхностного эффекта. По этой причине внутреннее поле в ферромагнитном цилиндре вблизи его поверхности с ростом частоты намагничивающего внешнего поля приближается к нему по амплитуде. Кроме того, обнаружено, что поле на поверхности неферромагнитного стержня, намагничиваемого переменным полем, с ростом частоты этого поля заметно превосходит его по напряженности.

Ключевые слова: переменное магнитное поле, поверхностный эффект, размагничивающий коэффициент, магнитные полюса, поверхностный эффект, вихревые токи, внутреннее поле, глубина проникновения, эффект Холла, микросхема.

\section{1. Введение}

Если теория намагничивания неферромагнитных проводящих предметов гармоническим переменным полем разработана достаточно полно [1-4], то изучение намагничивания таким полем ферромагнитных предметов продолжается, принося новые, не всегда ожидаемые сведения [5-7].

Известно, что при намагничивании кругового продолговатого цилиндра из неферромагнитного металла продольным переменным полем в его теле возникают концентрические вихревые токи, перпендикулярные вектору намагничивающего поля. Эти токи обусловливают появление в теле цилиндра переменного магнитного поля, направленного вдоль его оси и, начиная с некоторой частоты, противофазного намагничивающему полю. Следствием этого является монотонное убывание результирующего намагничивающего поля по мере углубления в тело цилиндра, названное поверхностным эффектом и, в первом приближении, подчиняющееся экспоненциальному закону. Расстояние вдоль радиуса цилиндра, на котором напряженность проникающего в него переменного поля убывает в $e$ раз, названо глубиной проникновения [1-4]. Если обозначить ее $a$, то

$$
a=\sqrt{\frac{2}{\mu_{0} \cdot \mu \cdot \sigma \cdot \omega}},
$$

где $\mu_{0}$-магнитная постоянная; $\mu$ - относительная магнитная проницаемость материала изделия; $\sigma-$ его удельная электропроводность и $\omega-$ круговая частота намагничивающего поля. 
Введение в формулу (1) относительной магнитной проницаемости материала цилиндра $\mu$ молчаливо предполагает, что проникновение переменного поля в ферромагнитный цилиндр, обладающий относительной проницаемостью, большей единицы, отличается от проникновения в неферромагнитный только количественно. Физическая картина проникновения предполагается совершенно одинаковой.

Между тем в [5-7] показано, что намагничивание ферромагнитного цилиндра переменным магнитным полем существенно отличается от намагничивания неферромагнитного. В частности, было установлено, что широко распространенный в теории вихревых токов обобщенный вихретоковый параметр $\beta$, описываемый выражением

$$
\beta=R \cdot \sqrt{\mu_{0} \cdot \mu \cdot \sigma \cdot \omega}
$$

где $R$ - радиус намагничиваемого цилиндра, в полной мере применим только для описания процессов намагничивания неферромагнитных изделий и обусловливает существенные погрешности при попытках его использования в случае ферромагнитных.

Предлагаемая статья посвящена изложению результатов дальнейшего изучения намагничивания ферромагнитного цилиндра переменным магнитным полем.

Как известно [8-10], при намагничивании постоянным полем вытянутого ферромагнитного изделия (в частности цилиндра) вблизи его концов возникают магнитные полюса, которые могут быть интерпретированы как воображаемые магнитные заряды. Поле этих полюсов внутри цилиндра (и вблизи него) направлено навстречу внешнему намагничивающему полю и, в той или иной степени, компенсирует это поле (рис. 1).

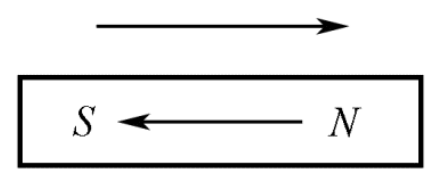

Рис. 1. Ориентация магнитных полей в протяженном ферромагнетике

На рис. 1 схематично представлен продолговатый ферромагнитный предмет (например стержень), намагничиваемый постоянным полем $H_{e}$, ориентированным слева направо. На левом конце предмета образуется южный магнитный полюс $S$, поскольку силовые линии внешнего поля входят в него, на правом конце - северный полюс $N$. Между образовавшимися полюсами возникает размагничивающее поле $H_{d}$, направленное навстречу внешнему намагничивающему.

В результате в намагничиваемом предмете будет действовать внутреннее поле $H_{i}$, являющееся результатом алгебраического суммирования полей:

$$
H_{i}=H_{e}-H_{d}
$$

Из простых физических соображений следует, что размагничивающее поле $H_{d}$ должно быть пропорционально намагниченности предмета $M$ и некоторому параметру $N$, зависящему от геометрических свойств (формы) намагничиваемого предмета. В этом случае выражение (3) может быть записано так:

$$
H_{i}=H_{e}-N \cdot M
$$

Намагниченность ферромагнитного предмета определяется [8] выражением

$$
M=k \cdot H_{i}
$$

где $k$ - магнитная восприимчивость его материала. 
Параметр $N$, называемый размагничивающим коэффициентом $[8,9]$ и характеризующий интенсивность размагничивающего поля, создаваемого магнитными зарядами на торцах ферромагнитного предмета (при неизменной намагниченности), из простых физических соображений тем больше, чем больше поперечное сечение предмета (в данном случае на его торцах) и тем меньше, чем больше расстояние между полюсами. А поскольку поле, создаваемое магнитным полюсом, убывает пропорционально квадрату расстояния от него, то коэффициент $N$, в конечном счете, является функцией параметра $\lambda$.

$$
N \approx \frac{1}{\lambda^{2}}
$$

где, в случае предмета в виде кругового цилиндра:

$$
\lambda=\frac{l}{d} .
$$

Здесь $l$ - длина, a $d$ - диаметр ферромагнитного цилиндра. Геометрический параметр $\lambda$ называется коэффициентом удлинения цилиндра и входит в общеизвестные формулы для расчетов размагничивающих коэффициентов [9].

При переходе к рассмотрению намагничивания ферромагнитного цилиндра переменным гармоническим полем возникает вопрос о поведении размагничивающего коэффициента $N$. Если при малых частотах намагничивающего поля оно проникает без ослабления на всю глубину изделия, то с повышением частоты оно проникает на все меньшую глубину. В таком случае уменьшается площадь магнитных полюсов, возникающих на торцах цилиндра, и соответственно уменьшается действующий при этом размагничивающий коэффициент цилиндра.

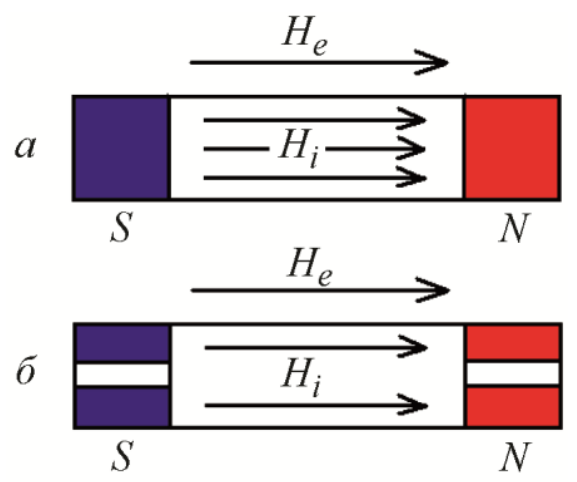

Рис. 2. Конфигурация магнитных зарядов на концах цилиндра: $a$ - намагничивание ферромагнитного цилиндра постоянным полем; $\sigma$ - намагничивание ферромагнитного цилиндра переменным полем

Это схематично представлено на рис. 2. Намагничивание ферромагнитного цилиндра внешним постоянным продольным магнитным полем $H_{e}$, направленным слева направо и проникающим на всю толщу, виртуальные магнитные заряды, созданные внутренним полем $H_{i}$, являющимся разностью внешнего намагничивающего и внутреннего размагничивающего и присутствующего, в том числе и на оси цилиндра, можно представить сплошными короткими цилиндриками на его концах (рис. $2 a$ ).

При намагничивании переменным полем созданные им магнитные полюса (заряды) периодически меняются местами. Внешнее поле ослабляется полем вихревых токов, протекающих вблизи поверхности по периметру цилиндра, и на оси цилиндра поле во много раз меньше, чем вблизи поверхности (скин-эффект). При достаточно высокой частоте перемагничивания плотность магнитных полюсов на оси цилиндра можно считать пренебрежимо 
малой. Можно считать, что магнитные полюса приобретают конфигурацию коротких трубочек меньшего объема, чем цилиндрики (рис. 2 б). Поскольку размагничивающее поле, создаваемое магнитным зарядом, пропорционально его величине, а величина заряда равна произведению намагниченности на его объем, то уменьшение зарядов на оси цилиндра имеет следствием и уменьшение создаваемого ими размагничивающего поля. Значит, при прочих равных условиях, в соответствии с выражениями (3)-(5), может уменьшаться доля размагничивающего поля и напряженность внутреннего поля в ферромагнетике вблизи поверхности с ростом частоты может приближаться к напряженности внешнего намагничивающего поля:

$$
H_{i} \rightarrow H_{e}
$$

На это обстоятельство обратил внимание ученый-физик Г.А. Бурцев еще в 1973 г. [11], однако тогда не было условий для экспериментальной проверки справедливости такого предположения. В предлагаемой статье излагаются результаты такой проверки.

\section{2. Материал и методика эксперимента}

Для достижения поставленной цели необходимо было измерить внутреннее поле $H_{i}$ вблизи поверхности цилиндра в зависимости от частоты $f$ намагничивающего поля $H_{e}$. Используя свойство непрерывности тангенциальной компоненты магнитного поля на границе сред с различающейся магнитной восприимчивостью $[8,12-15]$, поле вблизи внутренней поверхности ферромагнитного цилиндра с приемлемой точностью можно измерить в непосредственной близости к его внешней поверхности.

Традиционные измерительные катушки для этой цели применять затруднительно, поскольку требуется придавать им специфическую форму (рис. 3).

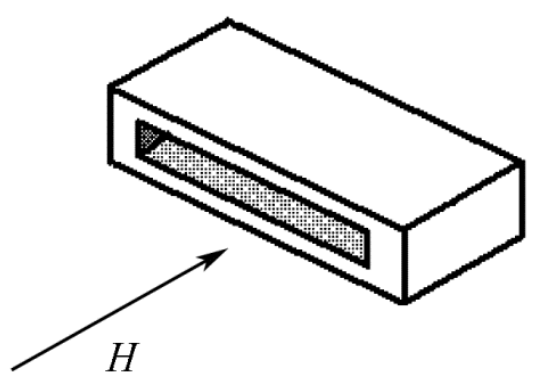

Рис. 3. Катушка для измерения внутреннего поля

Такая катушка должна обладать минимальным размером в высоту, чтобы воспринимать индукцию магнитного поля как можно ближе к поверхности испытуемого изделия. Но в таком случае площадь магнитного потока, охватываемого катушкой, минимальна, а значит, ничтожна и ЭДС, наводимая в ней (особенно при малых частотах измеряемого поля).

Появление микросхемных преобразователей магнитного поля, обладающих толщиной корпуса всего в один миллиметр, позволило устранить препятствия для измерения магнитных полей в непосредственной близости от поверхности намагниченного предмета. В нашем случае был применен микросхемный преобразователь магнитного поля 1SA-IV фирмы Sentron $[16,17]$, работающий на эффекте Холла. Преобразователь позволяет измерять магнитное поле вдоль длины обследуемого цилиндра на расстоянии порядка 0,2-0,3 мм от его поверхности. При подаче на электроды питания постоянного напряжения 6 в преобразователь (в отсутствие измеряемого магнитного поля) выдает на своем выходе 3 в постоянного напряжения. В приложенном постоянном магнитном поле напряженностью от -4 кА/м до 4 кА/м выходное напряжение преобразователя меняется в пределах от одного до пяти вольт при хорошей линейности преобразования. 
При помещении преобразователя в переменное магнитное поле на его выходе наблюдается переменное напряжение соответствующей частоты, пропорциональное амплитуде воздействующего поля. В паспортных данных нашего преобразователя [16] его частотные характеристики не приводятся. Поэтому они были измерены нами экспериментально. Результат измерения представлен на рис. 4.

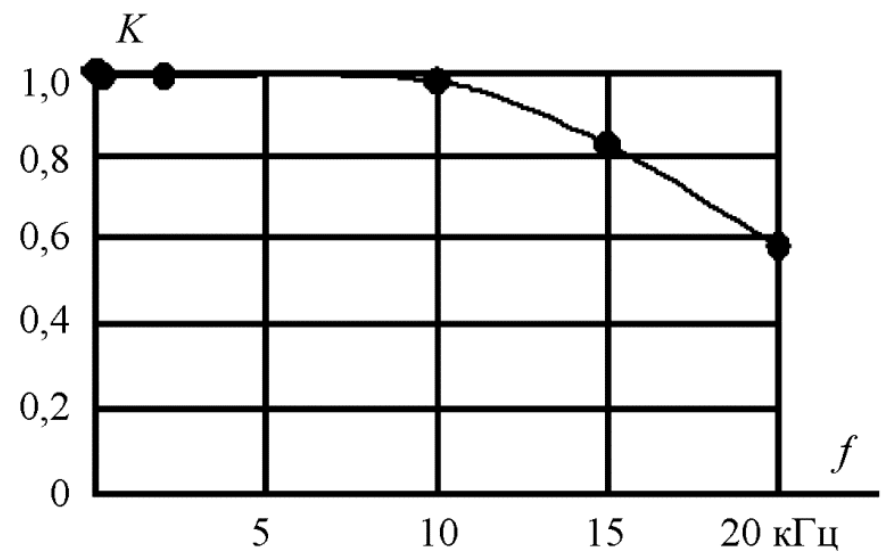

Рис. 4. Частотная характеристика преобразователя магнитного поля 1SA-IV.

По горизонтали - частота переменного поля; по вертикали - коэффициент преобразования относительно статического поля

Из рис. 4 следует, что характеристика преобразования выбранной нами микросхемы линейна вплоть до частоты 10 кГц, чего вполне достаточно для решения нашей задачи.

На рис. 5 показано расположение основных составляющих эксперимента.

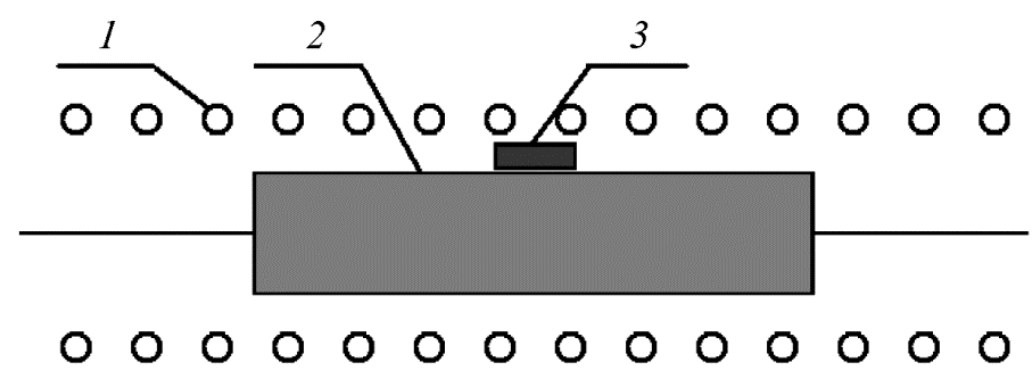

Рис. 5. Расположение составляющих эксперимента: 1 - соленоид, создающий переменное магнитное поле; 2 - объект исследования (круговой цилиндр или трубка); 3 - микросхемный преобразователь магнитного поля

На рис. 6 представлена блок-схема экспериментальной установки.

Установка работает следующим образом: звуковой генератор 1, вырабатывает переменное напряжение заданной частоты, которое поступает на соленоид 2, создающий переменное магнитное поле, намагничивающее исследуемый образец. Переменный ток, протекающий по соленоиду, вызывает падение переменного напряжения на образцовом резистоpe 3, включенном последовательно с соленоидом. Это переменное напряжение позволяет контролировать ток, протекающий по соленоиду, с помощью электронного милливольтметра 4. Переменное напряжение, вырабатываемое преобразователем магнитного поля 5, измеряется электронным милливольтметром 6. При переходе с одной заданной частоты на другую, ток, протекающий по соленоиду, контролируется милливольтметром 4 и поддерживается неизменным по амплитуде. 


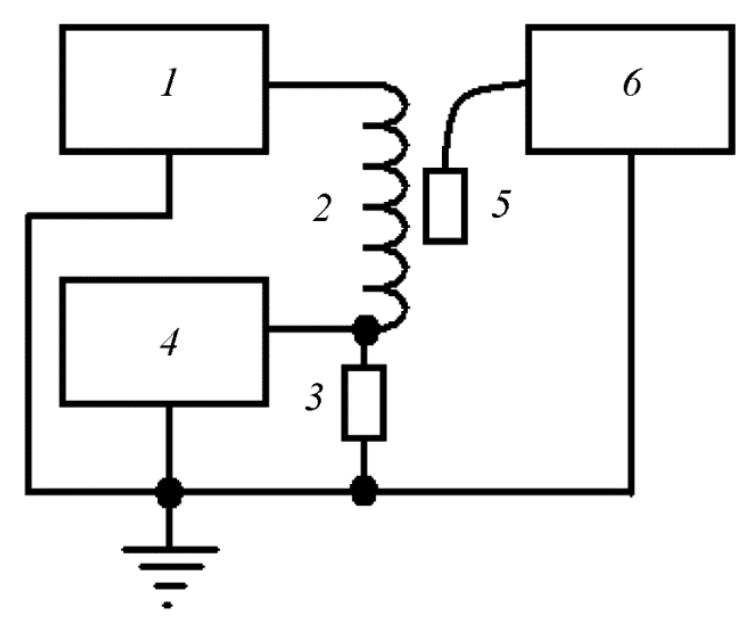

Рис. 6. Блок-схема экспериментальной установки: 1 - звуковой генератор; 2 - соленоид; 3 - образцовый резистор сопротивлением 0,51 Ом; 4 - милливольтметр; 5 - преобразователь магнитного поля; 6 - милливольтметр

Переменное магнитное поле, действующее на преобразователь 5, измеряется по величине переменного напряжения, поступающего на милливольтметр 6.

\section{3. Результаты и обсуждение}

На рис. 7 приведены результаты измерений зависимости поля вблизи поверхности ферромагнитных стержней от частоты намагничивающего поля. По оси абсцисс отложена частота намагничивающего поля амплитудой напряженности $150 \mathrm{~A} / \mathrm{M}$, а по оси ординат напряженность поля вблизи поверхности испытуемого ферромагнитного цилиндра в единицах напряженности намагничивающего поля. Кривая 1 соответствует цилиндру из стали Ст.3 диаметром 12 и длиной 50 мм, кривая 2 - такому же цилиндру длиной 78 мм и, наконец, кривая 3 - цилиндру длиной 132 мм.

Если считать, что поле, измеряемое преобразователем 1SA-IV, соответствует по напряженности полю внутри ферромагнитного цилиндра вблизи его поверхности, то из рис. 7 следует, что по мере возрастания частоты намагничивающего поля эффект размагничивающего действия магнитных полюсов вблизи торцов цилиндра монотонно убывает.

По горизонтали - частота намагничивающего поля. По вертикали - поле на поверхности стержня в единицах намагничивающего поля.

Вблизи нулевой частоты внутреннее поле в цилиндре тем меньше, чем меньше его коэффициент удлинения (при неизменном внешнем поле). Благодаря убыванию размагничивающего поля условия для намагничивания стержня с повышением частоты должны улучшаться. Однако этому препятствует возрастание влияния вихревых токов в теле стержня. В итоге поток индукции через поперечное сечение стержня с ростом частоты намагничивающего поля при неизменной амплитуде намагничивающего поля все же убывает.

На рис. 8. представлена зависимость потока индукции через поперечное сечение ферромагнитного цилиндра диаметром 12 и длиной 78 мм, полученная посредством измерения ЭДС, наводимой в измерительной катушке, размещенной посередине объекта исследования. 


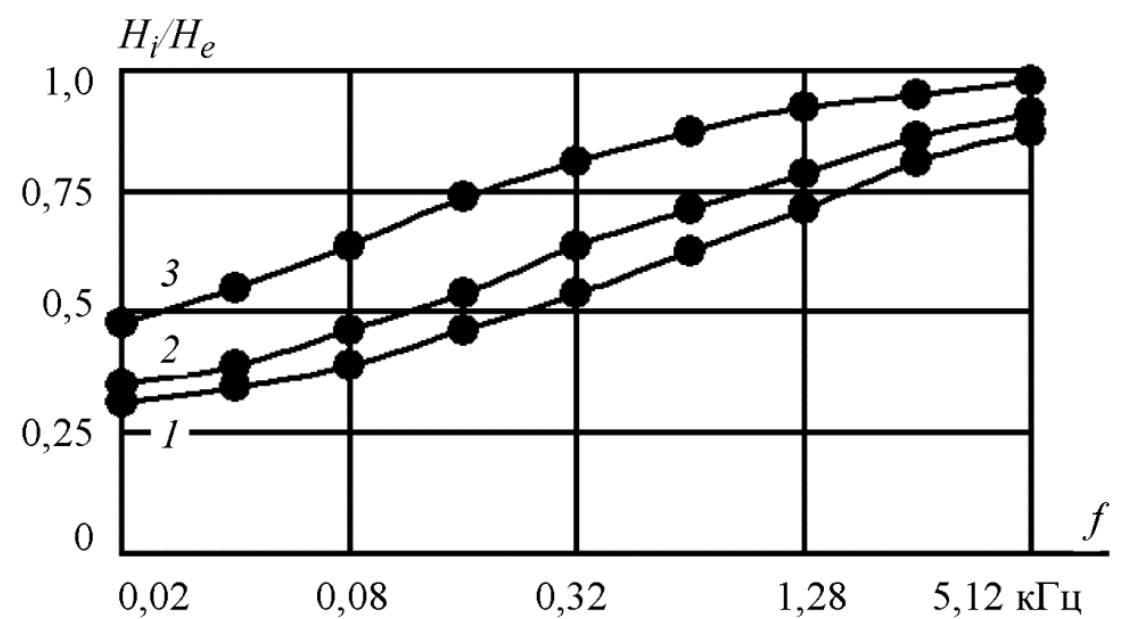

Рис. 7. Зависимость поля вблизи поверхности ферромагнитного стержня от частоты намагничивающего поля. По горизонтали - частота намагничивающего поля; по вертикали поле на поверхности стержня в единицах намагничивающего поля

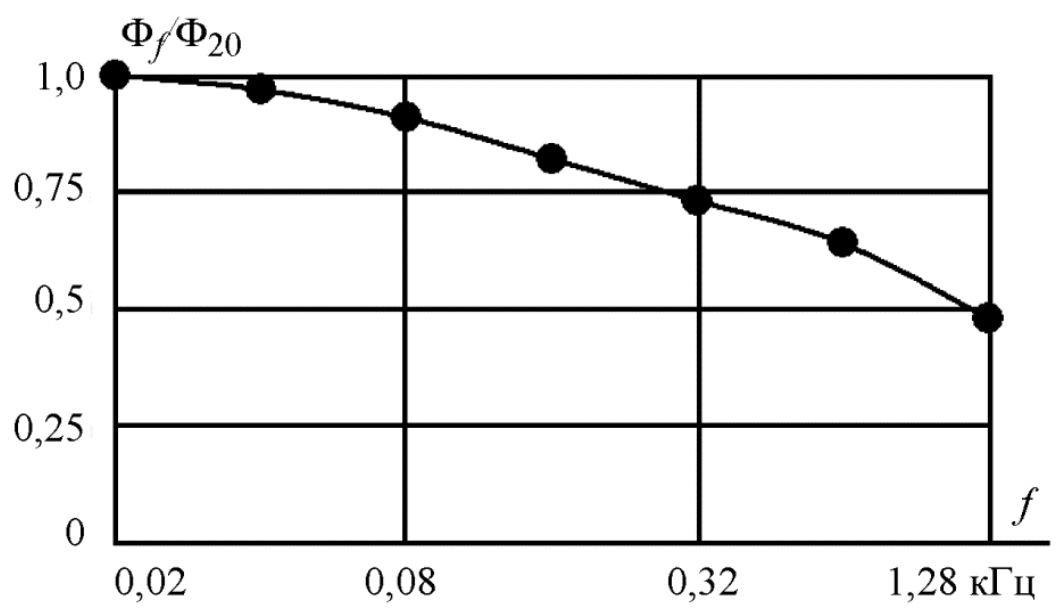

Рис. 8. Частотная зависимость потока индукции через центральное сечение ферромагнитного цилиндра. По горизонтали - частота намагничивающего поля; по вертикали - поток индукции на частоте наблюдения относительно потока при частоте 20 Гц

Представляет интерес исследование частотной зависимости поля на поверхности неферромагнитного проводящего цилиндра. Такая зависимость была измерена вблизи поверхности медного цилиндра диаметром 20 и длиной 75 мм (рис. 9). На ней также наблюдается некоторое увеличение доли поля на поверхности цилиндра относительно намагничивающего поля. 


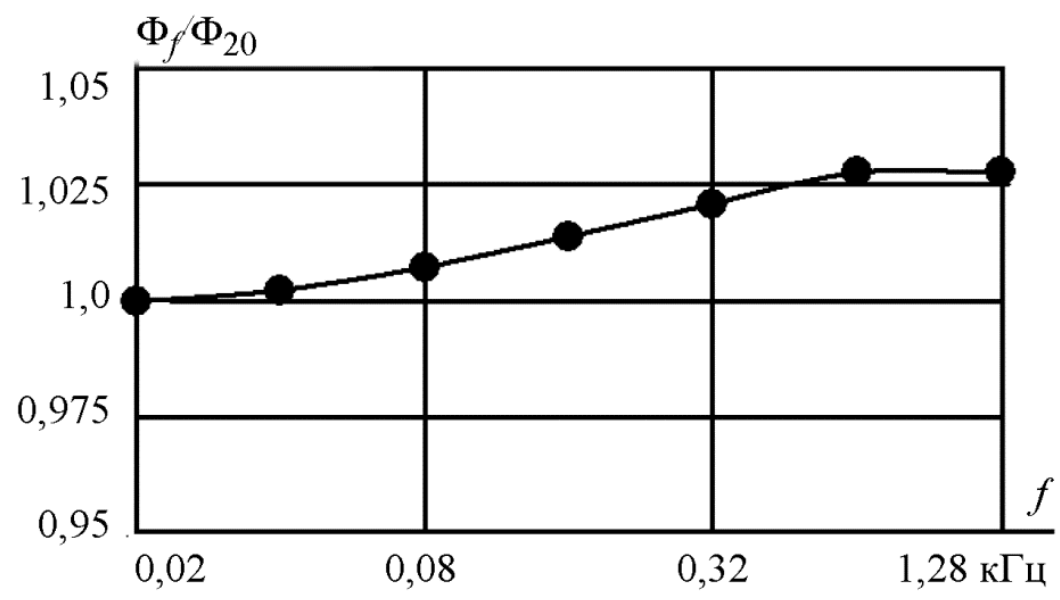

Рис. 9. Поле на поверхности медного цилиндра, намагничиваемого переменным полем. По горизонтали - частота намагничивающего поля; по вертикали - поле на поверхности цилиндра в единицах напряженности намагничивающего поля

Это возрастание не очень значительное, но выходит за рамки погрешностей измерения. Возникает вопрос о причинах его появления. По мнению автора, здесь проявляется поле вихревых токов, возникающих в теле обследуемого цилиндра. На рис. 10 изображены силовые линии магнитного поля, создаваемого вихревыми токами в толще цилиндра.

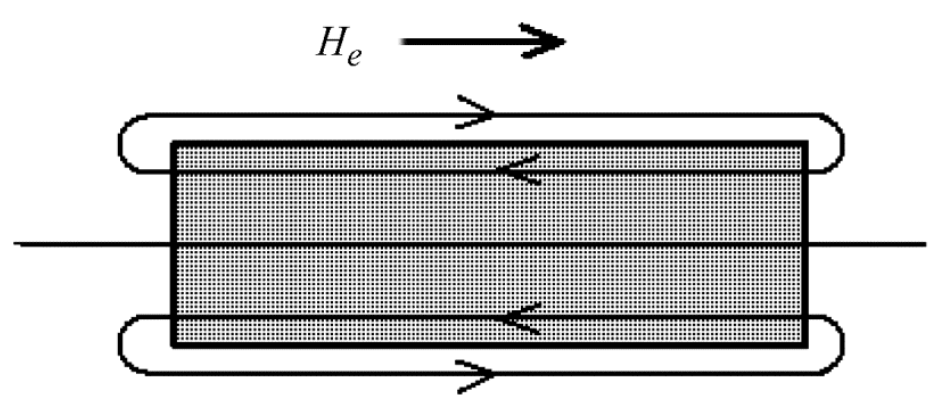

Рис. 10. Поле вихревых токов в диамагнитном цилиндре и вне его

Как и полагается, в толще цилиндра они направлены навстречу намагничивающему переменному полю [18], но вне цилиндра они совпадают по направлению с намагничивающим полем и слегка усиливают его, что и фиксирует преобразователь магнитного поля, размещенный на поверхности цилиндра.

\section{Намагничивание ферромагнитной трубки}

На рис. 11 представлены результаты измерений переменного магнитного поля на внешней и внутренней стенках ферромагнитной трубки, намагничиваемой вдоль продольной оси. Трубка была изготовлена из стали Ст5 и при длине 65 мм имела внешний диаметр 25 и внутренний 20 мм Преобразователи магнитного поля прикреплялись к внешней и внутренней стенкам трубки посередине ее длины с целью измерения полей, действующих вдоль оси. Еще один преобразователь размещался на оси трубки, посередине ее длины. С его помощью изучалось экранирование пространства в полости трубки от внешнего продольного магнитного поля. 


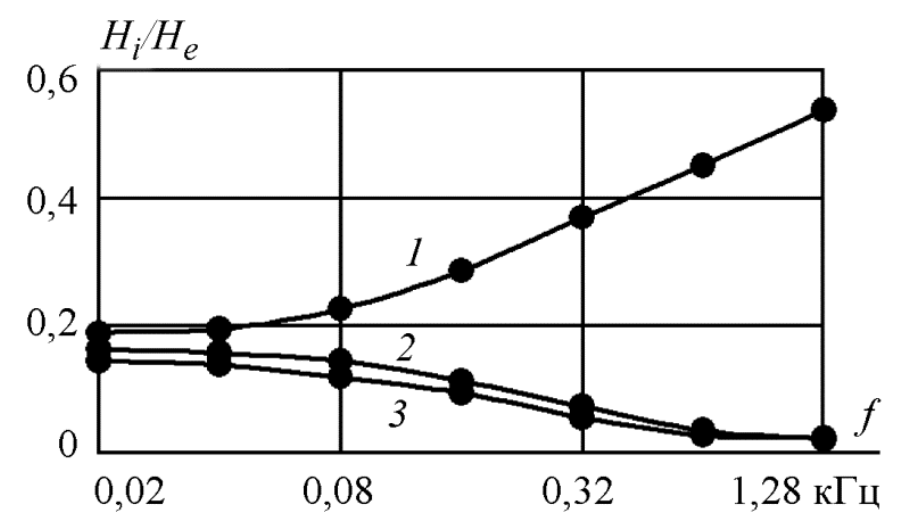

Рис. 11. Поля на внешней и внутренней стенках, а также в полости стальной трубки, намагничиваемой переменным полем. По горизонтали - частота намагничивающего поля, по вертикали - поле в различных местах трубки в долях намагничивающего.

Кривая 1 - поле на внешней стенке трубки; кривая 2 - поле на внутренней стенке; кривая 3 - поле в центре полости трубки

Сопоставление начальных участков кривых 1-3 показывает, что при малых частотах намагничивающего поля, когда намагничивание близко к статическому, внутреннее поле ослаблено действием размагничивающего поля полюсов на торцах трубки. Вблизи внутренней стенки трубки оно ослаблено несколько сильнее вследствие магнитостатического экранирования полости трубки от внешнего продольного поля [19]. Еще заметнее такое экранирование в центре полости трубки. По мере нарастания частоты намагничивающего поля растет, поле вблизи внешней стенки трубки (кривая 1), как и в случае сплошного ферромагнитного цилиндра (рис. 7). Поле вблизи внутренней стенки (кривая 2), как и в центре полости трубки (кривая 3), ослабляется с частотой под влиянием поля вихревых токов.

\section{4. Заключение}

Для измерения переменных магнитных полей в теле ферромагнитного предмета применен микросхемный преобразователь магнитного поля в электрический сигнал 1SA-IV, позволяющий измерять поле вдоль поверхности исследуемого объекта на расстоянии менее 0,5 мм от нее. Такое поле с достаточной степенью приближения может считаться соответствующим полю внутри тела объекта вблизи его стенки.

Измерением частотной характеристики преобразователя 1SA-IV была подтверждена его пригодность для измерения переменных магнитных полей с частотами до 10 кГц.

Измерениями на ферромагнитных цилиндрах показали, что размагничивающее поле магнитных полюсов, образующихся на торцах удлиненного ферромагнитного предмета, монотонно уменьшается с ростом частоты переменного намагничивающего поля по причине уменьшения размеров этих полюсов вследствие поверхностного эффекта. Использование при экспериментах ферромагнитных стержней с разными коэффициентами удлинения подтвердило прямую связь наблюдаемых эффектов с размагничивающими коэффициентами этих стержней.

Выявлено заметное увеличение переменного магнитного поля вблизи поверхности неферромагнитного стержня с возрастанием частоты намагничивающего поля. Такое увеличение, по мнению автора, объясняется влиянием поля вихревых токов, компенсирующих намагничивающее поле внутри намагничиваемого неферромагнитного объекта и несколько усиливающих это поле снаружи объекта.

Измерениями на ферромагнитной трубке доказано, что с возрастанием частоты намагничивающего поля оно ослабляется внутри нее - вблизи внутренней стенки, в то время как вблизи ее внешней стенки оно возрастает. 
Выполненные исследования позволили получить новые, ранее неизвестные сведения о процессах в ферромагнитных предметах при их намагничивании переменным полем. Сведения эти могут оказаться полезными как в теоретическом плане, так и при интерпретации полученных экспериментальных материалов.

Использование современных достижений микроэлектронной промышленности открывает новые возможности для экспериментального изучения электромагнитных процессов в ферромагнитных объектах.

\section{Благодарность}

Работа выполнена в рамках государственного задания МИНОБРНАУКИ России (тема «Диагностика», № АAАA-A18-118020690196-3).

\section{Литература}

1. Дорофеев А. Л. Неразрушающие испытания методом вихревых токов. - М. : Оборонгиз, 1961. - $158 \mathrm{c.}$

2. Ламмеранер Й., Штафль М. Вихревые токи / пер. с чеш. - Москва - Ленинград : Энергия, 1967. - 208 с.

3. Неразрушающий контроль качества изделий электромагнитными методами / В. Г. Герасимов, Ю. Я. Останин, А. Д. Покровский, В. В. Сухоруков, Л. А. Чернов. - М. : Энергия, 1978. - 215 с.

4. Неразрушающий контроль. Т. 2 / под ред. В. В. Клюева. - М. : Машиностроение, 2005. $-688 \mathrm{c}$.

5. Reutov Y. Y., Shcherbinin V. E. On complex permeability in eddy-current flaw detection, defektoskopiya // Russian Journal of Nondestructive Testing. - 2012. - Vol. 48, no. 12. - P. 693-699. DOI: 10.1134/S1061830912120054.

6. Reutov Yu. Ya. The causes of the hodograph anomalies of a vortex-current converter // Russian Journal of Nondestructive Testing. - 2012. - Vol. 51, no. 12. - P. 759-767. DOI: $10.1134 /$ S1061830915120086.

7. Реутов Ю. Я. Обобщенный вихретоковый параметр, границы применимости // Электричество. - 2016. - № 7. - С. 42-50.

8. Аркадьев В. К. Электромагнитные процессы в металлах. Ч. 1. - Москва; Ленинград : НКТП СССР. Объед. науч.-техническое изд-во. Главная ред. энергетической литературы, 1934-1936. - 230 c.

9. Чечерников В. И. Магнитные измерения. - Изд. 2, перераб. и доп. - Издательство Московского университета, 1969. - 388 с.

10. Туровский Я. Техническая электродинамика / пер. с польского. - М. : Энергия, 1974. $488 \mathrm{c}$

11. Бурцев Г. А. К динамике перемагничивания ферромагнитных стержней конечной длины в слабых магнитных полях. - Дефектоскопия. - 1973 - № 5 - С. 34-42.

12. Тамм И. Е. Основы теории электричества. - М. : Наука, 1976. - 616 с.

13. Янус Р. И., Магнитная дефектоскопия. - Москва ; Ленинград : Гостехиздат, 1946. $171 \mathrm{c}$.

14. Веденев М. А., Дрожжина В. И. Об измерении коэрцитивной силы накладным датчиком. - Дефектоскопия. - 1977. - № 5. - С. 65-73.

15. Веденев М. А. Измеритель тангенциальной составляющей постоянного магнитного поля на поверхности образца. - Дефектоскопия. - 1982. - № 2. - С. 89-91.

16. URL: www.sentron.ch

17. Reutov Y. Y., Shcherbinin V. E., Volkov A. V. Possibilities for the selection of magnetic field transducers for nondestructive testing // Russian Journal of Nondestructive Testing. - 2014. Vol. 50, no. 12. - P. 760-768. - DOI: 10.1134/S1061830914120080. 
18. Reutov Yu. Ya. The characteristic of an object revealed by its magnetic field // Russian Journal of Nondestructive Testing. - 1998. - Vol. 34, no. 2. - P. 77-83.

19. Reutov Yu. Ya. Ferrite-ring magnetostatic screens // Russian Journal of Nondestructive Testing. - 1999. - Vol. 35 (5). - P. 334-338. 